\title{
Salt or no salt in the treatment of cirrhotic ascites: A randomised study
}

\author{
A GAUTHIER, V G LEVY, A QUINTON, H MICHEL, B RUEFF, \\ L DESCOS, J P DURBEC, J FERMANIAN, S LANCRENON, AND \\ THE ENTAC GROUP* \\ From the Clinique d'hépato-gastro-entérologie, Hopital de la Conception, Marseille, Service \\ d'hépato-gastro-entérologie A, Hopital Saint-Antoine, Paris, Services des maladies de l'appareil digestif, \\ Hopital Saint-André, Bordeaux, Clinique des maladies de l'appareil digestif, Hopital Saint-Eloi, Montpellier, \\ Service d'hépato-gastro-entérologie, Hopital Beaujon, Clichy, Service d'hépato-gastro-entérologie et \\ médecine interne, Hopital Edouard Herriot, Lyon, INSERM U 31, Hopital Sainte-Marguerite, Marseille, and \\ INSERM U 88, Hopital de la Pitié, Paris, France
}

SUMmaRY To compare the effect of diet, cirrhotic patients with ascites were randomised into two treatment groups: (1) a low sodium diet $(21 \mathrm{mmol})$ per day or (2) an unrestricted sodium intake. Both groups received effective doses of diuretics (spironolactone or, if necessary, spironolactone and furosemide. One hundred and forty patients from 12 liver units were included according to well defined criteria (group 1: 76; group 2: 64). After an initial four to seven day period of bed rest and salt restriction $(21 \mathrm{mmol}$ sodium $\mathrm{pd})$, randomisation was done in each centre. We saw no significant difference between the two groups with respect to (1) clinical and biochemical data; (2) mortality or withdrawal (definitive or temporary) because of biochemical disturbances (group 1: $34 \%$, group 2: $22 \%$ ); (3) the time for complete disappearance of ascites was significantly shorter $(p=0.014)$ for the salt restricted patients (4) actuarial survival (curves plotted up to the 120th day) was not statistically different $(p=0 \cdot 18)$, but division into subgroups using various prognostic factors showed that survival was significantly better for salt restricted patients without previous gastrointestinal bleeding $(\mathrm{p}=0.02) ;(5)$ hospitalisation time and costs were identical in both groups. We conclude that the advantage of a normal salt diet was not shown in this study.

The treatment of cirrhotic ascites usually includes a salt restricted diet and the prescription of diuretics. ${ }^{1-3}$ This treatment often results in clinical complications ${ }^{4}$ - that is, cramps, loss of appetite with consequent nutritional deterioration and/or biochemical abnormalities, hyponatremia, uraemia, hypo or hyperkaliemia. It has been suggested that a normal salt diet would prevent the occurrence of short term electrolytic and renal disorders. ${ }^{5}$ This was not confirmed, however, by work subsequently carried out in 33 French liver units. ${ }^{6}$ Our study was undertaken to test the following hypotheses: (a) An

\footnotetext{
Address for correspondence: Professor A Gauthier, Hopital de la Conception. 13005 Marseille. France.

*The ENTAC Group: National Inquiry for the Treatment of Cirrhotic Ascites. Co-investigators: P Bergerault (Vannes). M Bouvry (Pontoise). J P Capron (Amiens), J L Consigny (Chalon-sur-Marne), H Fraisse (Saint-Etienne), J Lafon (Aix-en-Provence), J Leblanc (Cannes), B Liberelle (Grenoble), J Roche (Grenoble).
}

unrestricted diet in association with diuretics decreases the occurence of short term (14 days) biochemical complications. (b) By increasing appetite, such a diet will improve nutrition and increase medium term (90 days) survival.

\section{Methods}

Twelve liver units took part in this study. The patients included had alcoholic cirrhosis, confirmed by the usual clinical and biological data: detection of hepatomegaly, spider naevi, oesophageal varices, ascites confirmed by paracentesis, serum albumin below $30 \mathrm{~g} / \mathrm{l}$. Quick time - that is, prothrombin time expressed as a percentage of prothrombin time of control subject, below $60 \%$, observation of cirrhosis by laparoscopy and/or liver biopsy.

Ascites was confirmed by a $20 \mathrm{ml}$ abdominal paracentesis enabling examination of ascitic fluid for 
cytology and bacteriological culture. Patients included were estimated, by clinical examination, to have at least four to five litres of ascitic fluid.

\section{EXCLUSION CRITERIA}

Patients were excluded for the following reasons: if below 20 years of age, the inability to attend regular follow up, the requirement of emergency treatment, the presence of chronic hepatic encephalopathy, haemorrhagic ascites (macroscopic appearance), tuberculosis, or extra hepatic cancer, the development of hepatocellular carcinoma during the study, a positive HBs antigen and temporary exclusion criteria persisting for more than three weeks.

Patients having one of the following disorders were temporarily excluded: gastrointestinal bleeding, acute hepatic encephalopathy, a temperature greater than $38^{\circ} \mathrm{C}$, infected ascites (more than 300 leukocytes $/ \mathrm{mm}^{3}$ ), diarrhoea, blood urea greater than $8.3 \mathrm{mmol} / \mathrm{l}$, plasma sodium less than $130 \mathrm{mmol} / \mathrm{l}$, plasma potassium concentration less than 3.5 or greater than $5.5 \mathrm{mmol} / \mathrm{l}$, serum bilirubin greater than $85 \mu \mathrm{mol} / \mathrm{l}$.

\section{TREATMENT}

Patients were observed initially during a four to seven day period of bed rest. Salt intake was restricted to $21 \mathrm{mmol}$ and water to one litre per day. The patient was then either randomised to a treatment group, definitively excluded, or temporarily excluded. If temporarily excluded, the observation period was extended one or two weeks. If exclusion criteria remained applicable at three weeks, the patient was definitively excluded.

Both therapeutic protocols included diuretics, and differed only in diet. In group 1, sodium intake was restricted to $21 \mathrm{mmol} /$ day and in group 2, it was unrestricted. The diuretics, spironolactone (Aldactone ${ }^{\circledR}$ ) and furosemide (Lasilix ${ }^{\circledR}$ ) were used in four day increments as follows: initially $200 \mathrm{mg}$ of spironolactone, increased if weight loss was less than $1 \mathrm{~kg}$ in total over the preceding four day period to $400 \mathrm{mg}$ and then to $600 \mathrm{mg}$. If $600 \mathrm{mg}$ of spironolactone was insufficient, $40 \mathrm{mg}$ of furosemide was added and if necessary, increased to $80 \mathrm{mg}$. Medication was given once daily for the starting dose and if increased, divided into a twice daily regimen.

The following data were collected twice a week: weight, abdominal girth, urine volume, adverse effects of treatment, blood urea, and plasma/urine ratios of sodium and potassium. Treatment was interrupted whenever the patient's weight dropped by more than $1 \mathrm{~kg} / \mathrm{day}$, when gastrointestinal bleeding or diarrhoea occurred, if blood urea was greater than $13 \mathrm{mmol} / \mathrm{l}$ or plasma sodium below $125 \mathrm{mmol} / \mathrm{l}$. Treatment was resumed if these dis- orders disappeared within one week. If these abnormalities persisted for longer than one week, recurred on restarting treatment, or if treatment proved ineffective at maximum diuretic dosage patients were withdrawn and prognosis considered unfavourable.

Results were assessed on the 14th day and after three months. The assessment criteria were: disappearance of ascites assessed by clinical examination (complete disappearance, disappearance followed by relapse, partial disappearance, no disappearance), change in weight and abdominal girth, survival, assessment of nutritional status (clinically assessed as normal or obese, moderate malnutrition, severe malnutrition), appetite, the occurrence of cramps and biological tolerance - that is, biochemical parameters remaining within range specified above.

\section{STATISTICAL METHODS}

Patients were randomised between the two therapeutic protocols with stratification by centre. Mean and standard deviation were used to describe quantitative variables (our results are listed as mean $\pm \mathrm{SD}$ in the Tables) and the two therapeutic protocols were compared by Fisher test. Percentage and $\chi^{2}$ test were used to describe and compare the two therapeutic protocols for qualitative variables. For comparison of the prothrombin level, the Mann and Whitney test was used (non-parametric statistic).

Survival curves were calculated according to the method of Kaplan and Meier, ${ }^{7}$ Log Rank test ${ }^{8}$ was used to evaluate differences in survival curves. The factors likely to influence survival such as sex, age, nutritional status, previous gastrointestinal bleeding, pretreatment before randomisation were analysed.

Table 1 Clinical data before treatment

\begin{tabular}{|c|c|c|c|}
\hline & $\begin{array}{l}\text { Salt restricted } \\
\text { diet }\end{array}$ & $\begin{array}{l}\text { Unrestricted } \\
\text { diet }\end{array}$ & \\
\hline Patients (no) & 76 & 64 & \\
\hline Age (years) & $58 \cdot 2 \pm 9 \cdot 5$ & $57 \cdot 3 \pm 11 \cdot 7$ & NS \\
\hline $\operatorname{Men}(\%)$ & 74 & 83 & NS \\
\hline Weight $(\mathrm{kg})$ & $69 \cdot 5 \pm 12$ & $67 \cdot 9 \pm 12 \cdot 5$ & NS \\
\hline Abdominal girth $(\mathrm{cm})$ & $102 \pm 10$ & $100 \pm 12$ & NS \\
\hline Gastrointestinal blceding ( $\%)$ & 21 & 17 & NS \\
\hline \multicolumn{4}{|l|}{ Nutritional status } \\
\hline Normal or obese $(\%)$ & 45 & 42 & \\
\hline Moderate malnutrition (\%) & 47 & 44 & NS \\
\hline Severe malnutrition $(\%)$ & 8 & 14 & \\
\hline \multicolumn{4}{|l|}{ Apetite } \\
\hline Good $(\%)$ & $27 \cdot 6$ & 35 & \\
\hline Medium $(\%)$ & 62 & $55 \cdot 5$ & NS \\
\hline Poor $(\%)$ & $10 \cdot 4$ & $9 \cdot 5$ & \\
\hline
\end{tabular}




\section{Results}

One hundred and forty patients were included in the study: 76 had a salt restricted diet and 64 had an unrestricted diet. There were no significant differences before treatment between each group with respect to clinical (Table 1) and laboratory data (Table 2).

Patient follow up withdrawal and deaths are summarised in Figure 1. There were no significant differences between the groups in withdrawal rate, or in the incidence of temporary interruption of the treatment $(34 \%$ in group I, $22 \%$ in group II). The main clinical and biochemical data on the 14th day are shown in Table 3, and on the 90th day in Table 4.

SURVIVAL

Crude survival and actuarial curves were compared for the two groups. (a) Crude data: at 90 days, there

Table 2 Biochemical data before treatment

\begin{tabular}{|c|c|c|c|}
\hline & $\begin{array}{l}\text { Salt restricted } \\
\text { diet }\end{array}$ & $\begin{array}{l}\text { Unrestricted } \\
\text { diet }\end{array}$ & \\
\hline Patients (no) & 76 & 64 & \\
\hline Serum bilirubin $(\mu \mathrm{mol} / \mathrm{l})$ & $40 \cdot 5 \pm 26$ & $34 \cdot 5 \pm 18 \cdot 5$ & NS \\
\hline Serum albumin $(g / l)$ & $28 \cdot 5 \pm 5$ & $27 \cdot 4 \pm 4 \cdot 5$ & NS \\
\hline $\begin{array}{l}\text { Prothrombin time expressed as } \\
\text { a percentage of normal }\end{array}$ & $\begin{array}{l}\text { Median: } 53 \\
\text { Ranges: } 27-100\end{array}$ & $\begin{array}{ll}\text { Median: } & 56 \cdot 5 \\
\text { Ranges: } & 25-100\end{array}$ & \multirow[t]{2}{*}{ NS } \\
\hline \multicolumn{3}{|l|}{ Aspartate amino transferase } & \\
\hline Normal $(\%)$ & 41 & 45 & \multirow{3}{*}{ NS } \\
\hline 2 to $4 \times$ normal $(\%)$ & 54 & 50 & \\
\hline More than $4 \times$ normal $(\%)$ & 5 & 5 & \\
\hline Scrum sodium $(\mathrm{mmol} / \mathrm{l})$ & $136 \pm 3$ & $135 \pm 4$ & NS \\
\hline Serum potassium $(\mathrm{mmol} / \mathrm{l})$ & $3 \cdot 8 \pm 0 \cdot 5$ & $3 \cdot 8 \pm 0 \cdot 5$ & NS \\
\hline Blood urea $(\mathrm{mmol} / \mathrm{l})$ & $3 \cdot 7 \pm 1 \cdot 7$ & $4 \pm 1 \cdot 7$ & NS \\
\hline \multicolumn{4}{|l|}{ Urinary excretion $(\mathrm{mmol} / 24 \mathrm{~h})$} \\
\hline Sodium & $23 \cdot 9 \pm 36.6$ & $38 \cdot 3 \pm 58 \cdot 7$ & NS \\
\hline Potassium & $26 \cdot 7 \pm 25 \cdot 8$ & $33 \cdot 5 \pm 32 \cdot 3$ & NS \\
\hline
\end{tabular}

Table 3 Clinical and biochemical data on 14th day of treatment

\begin{tabular}{|c|c|c|c|}
\hline & $\begin{array}{l}\text { Salt restricted } \\
\text { diet }\end{array}$ & $\begin{array}{l}\text { Unrestricted } \\
\text { diet }\end{array}$ & \\
\hline Patients under treatment & 74 & 61 & \\
\hline \multicolumn{4}{|l|}{ Ascites } \\
\hline Complete disappearance $(\%)$ & 42 & 23 & NS \\
\hline Partial disappearance $(\%)$ & 57 & $60 \cdot 6$ & NS \\
\hline No disappearance $(\%)$ & 1 & $16 \cdot 4$ & $\mathrm{p}<0.01$ \\
\hline Loss of weight $(\mathrm{kg})$ & $8 \pm 4 \cdot 3$ & $5 \cdot 4 \pm 4$ & $\mathrm{p}<0 \cdot 001$ \\
\hline Decrease in abdominal girth $(\mathrm{cm})$ & $9 \cdot 9 \pm 6$ & $5 \cdot 8 \pm 4$ & $\mathrm{p}<0.001$ \\
\hline \multicolumn{4}{|l|}{ Appetite } \\
\hline Equal or less $(\%)$ & $63 \cdot 5$ & 82 & \\
\hline Improve $(\%)$ & $36 \cdot 5$ & 18 & $\mathrm{p}<0.02$ \\
\hline \multicolumn{4}{|l|}{$\%$ of patients taking maximum } \\
\hline spironolactone dose & 12 & 26 & $\mathrm{p}<0.04$ \\
\hline Blood urea $(\mathrm{mmol} / \mathrm{l})$ & $4 \cdot 7 \pm 2 \cdot 2$ & $5 \cdot 3 \pm 5 \cdot 7$ & NS \\
\hline Difference 14th day - 1st day & ${ }^{*} 1 \pm 1 \cdot 8$ & ${ }^{*} 0.7 \pm 1.6$ & NS \\
\hline Serum sodium $(\mathrm{mmol} / \mathrm{l})$ & $132 \pm 4$ & $133 \pm 4$ & NS \\
\hline Difference 14th day - 1st day & $+4 \pm 4 \cdot 3$ & $+2 \cdot 4 \pm 3 \cdot 6$ & $S(p=0 \cdot(225)$ \\
\hline Serum potassium $(\mathrm{mmol} / \mathrm{l})$ & $4 \cdot 5 \pm 0 \cdot 5$ & $4 \cdot 3 \pm 0 \cdot 4$ & NS \\
\hline Difference 14th day-1st day & $* 0 \cdot 6 \pm 0 \cdot 6$ & ${ }^{*} 0 \cdot 5 \pm 0 \cdot 5$ & NS \\
\hline Urine volume $(\mathrm{ml} / 24 \mathrm{~h})$ & $* 699 \pm 674$ & $* 521 \pm 654$ & NS \\
\hline Urine sodium $(\mathrm{mmol} / 24 \mathrm{~h})$ & $84 \cdot 7 \pm 117 \cdot 5$ & $99 \pm 129 \cdot 4$ & NS \\
\hline Urine potassium $(\mathrm{mmol} / 24 \mathrm{~h})$ & ${ }^{*} 29 \cdot 4 \pm 44.9$ & $* 17 \cdot 6 \pm 5() \cdot 5$ & NS \\
\hline
\end{tabular}




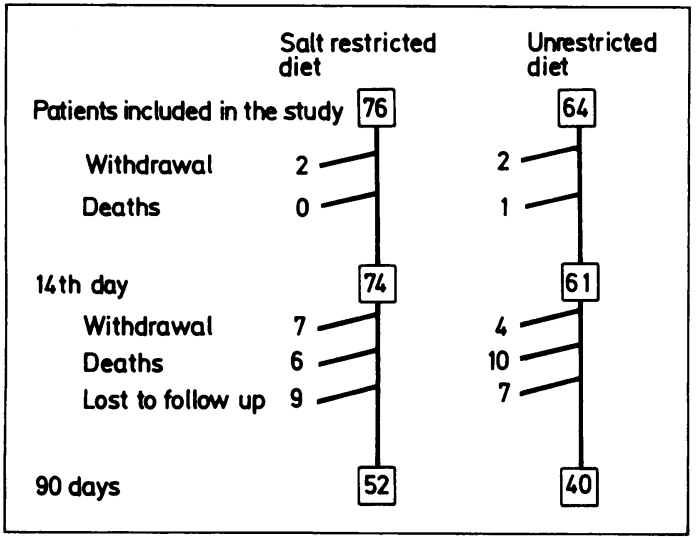

Fig. 1 Outcome during follow up for 140 patients in the treatment groups

were six deaths in the salt restricted groups, versus 11 deaths in the unrestricted diet $(p=0 \cdot 15)$. (b) Actuarial survival : curves were plotted up to the 120th day: the difference between the two groups is not statistically significant $(p=0 \cdot 18)$ (Fig. 2). The survival curves were compared between the two groups described in the protocol and also to subgroups defined by the various prognostic factors listed above. Among these, the only significant result was seen in the patients without previous gastrointestinal bleeding, in favour of salt restricted protocol $(p=0.02)$ (Fig. 3). In this subgroup of patients, there was no difference in initial clinical and laboratory data between the two therapeutic protocol groups.
HOSPITALISATION AND COSTS

These were identical in both groups: $27 \cdot 9 \pm 14 \cdot 8$ days in group I, against $27 \cdot 4 \pm 15 \cdot 1$ in group II. Cumulative drug doses were not significantly different at three months.

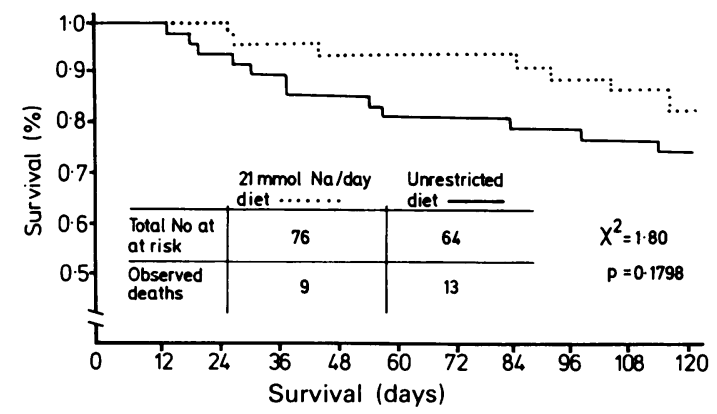

Fig. 2 Actuarial curves of survival according to diet for total population

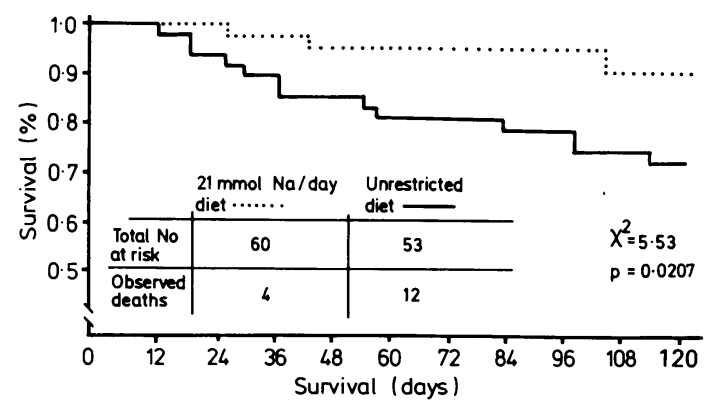

Fig. 3 Survival curves according to diet for the 113 patients with no gastrointestinal bleeding before study

Table 4 Clinical and biochemical data for patients under treatment on 90th day

\begin{tabular}{|c|c|c|c|}
\hline & $\begin{array}{l}\text { Salt restricted } \\
\text { diet }\end{array}$ & $\begin{array}{l}\text { Unrestricted } \\
\text { diet }\end{array}$ & \\
\hline Patients (no) & 52 & 40 & \\
\hline \multicolumn{4}{|l|}{ Ascites disappearance } \\
\hline Complete $(\%)$ & $59 \cdot 6$ & $52 \cdot 6$ & \multirow{3}{*}{ NS } \\
\hline Complete with relapse $(\%)$ & 25 & $34 \cdot 2$ & \\
\hline Partial drying or failure $(\%)$ & $15 \cdot 4$ & $13 \cdot 2$ & \\
\hline Loss of weight $(\mathrm{kg})$ & $5 \cdot 9 \pm 6 \cdot 9$ & $6 \cdot 8 \pm 5 \cdot 6$ & NS \\
\hline Decrease in abdominal girth $(\mathrm{cm})$ & $12 \pm 9$ & $11 \pm 7$ & NS \\
\hline \multicolumn{4}{|l|}{ Appetite } \\
\hline Equal or less $(\%)$ & $51 \cdot 9$ & 50 & \multirow[b]{2}{*}{ NS } \\
\hline Improved & $48 \cdot 1$ & 50) & \\
\hline \multicolumn{4}{|l|}{ Nutritional status } \\
\hline Equal or less $(\%)$ & 71 & $67 \cdot 5$ & \multirow[b]{2}{*}{ NS } \\
\hline Improved & 29 & $32 \cdot 5$ & \\
\hline Increase in blood urea $(\mathrm{mmol} / \mathrm{l})$ & $+2 \cdot 14 \pm 5$ & $+0 \cdot 5 \pm 2$ & NS \\
\hline Serum sodium $(\mathrm{mmol} / \mathrm{l})$ & $135 \cdot 5 \pm 4 \cdot 3$ & $133 \cdot 4 \pm 5 \cdot 3$ & NS \\
\hline Difference 90th day - 1st day & $-0 \cdot 6 \pm 4 \cdot 3$ & $-2 \pm 6$ & NS \\
\hline Serum potassium & $4 \cdot 1 \pm(0 \cdot 5$ & $4 \cdot 2 \pm 0 \cdot 6$ & NS \\
\hline Difference 90th day - 1st day & $+0 \cdot 27 \pm 0 \cdot 8$ & $+(0.52 \pm 0.7$ & NS \\
\hline Albumin $(\mathrm{g} / \mathrm{l})$ & $32 \pm 6$ & $31 \cdot 2 \pm 6 \cdot 6$ & NS \\
\hline Difference 90)th day - 1st day & $+3 \cdot 5 \pm 7$ & $+3 \cdot 8 \pm 6$ & NS \\
\hline
\end{tabular}




\section{Discussion}

The study compared a $21 \mathrm{mmol}$ sodium diet and an unrestricted diet, associated with diuretics, in the treatment of cirrhotic ascites. The sodium balance was determined for each therapeutic group from salt input and output. It correlated with the observed weight loss for salt restricted patients on the 14th day and estimated a mean sodium intake for patients on a free diet of between $51 \mathrm{mmol}$ and $68 \mathrm{mmol} /$ day. Therefore an unrestricted diet, at least in hospital, for ascitic and probably anorectic patients, is a moderate and not a normal salt intake.

\section{TREATMENT EFFICACY}

At day 90, the resolution of ascites is identical in both groups. Disappearance of ascites occurs faster with a salt restricted diet, however, than with a free diet. This is shown by significant differences at day 14 in the number of patients without ascites, and by weight and abdominal girth differences. These differences are not found at three months (day 90). Actuarial curves of disappearance time of ascites also confirm these findings. The nutritional status that we hoped would be improved with a free, appetising diet is identical in both groups. Paradoxically, appetite seems to increase most often for salt restricted patients on the 14th day. This improvement could be related to a larger ascitic reduction in this group at this date.

\section{TOLERANCE}

Tolerance is also identical: the number of withdrawals because of biochemical disturbances during treatment, or cirrhotic complications, is similar in both groups at the 14th day and at the 90th day. Biochemical changes are similar except for a marked hyponatremia on the 14th day for salt restricted patients. This hyponatraemic tendency reported by Reynolds, ${ }^{1}$ is however, in this study, a transient phenomenon noted at the beginning of treatment. In contrast, the marked increase in blood urea, reported by Reynolds for salt restricted patients, was not found.

\section{SURVIVAL}

The salt restricted diet tends overall to improve survival $(p=0 \cdot 09)$. Survival is statistically better with salt restriction for the subgroup of patients without previous gastrointestinal bleeding. The reasons why are unclear. In fact, these positive findings could be due to chance considering the repeated tests used. Moreover we could not find any explanation of this unexpected favourable effect of the salt restricted diet. This result, however, has to be confirmed in a further prospective study.
TREATMENT costs

Although ascites disappear significantly faster with a salt restricted diet, this has no effect on hospitalisation time (taken as an essential cost factor in this work). Drug dosage, which also affects treatment costs, does not differ significantly.

We have compared the effects of a salt restricted diet and a free salt diet, associated with diuretics, for the treatment of medium severity ascites in alcoholic cirrhotics. With an unrestricted diet, decrease of serum sodium concentration is less marked but the disappearance of ascites is also less frequent, or less significant, in the patients at 14 days. Ascite disappearance, appetite, and nutritional status are identical at three months. The beneficial effects of a salt restricted diet seen at 14 days on the following parameters weight loss, abdominal girth, clinical assessment of ascites disappearance, and appetite are transient. There is no significant difference between the two groups at three months. In conclusion, we have demonstrated a transient beneficial effect of a salt restricted diet; although not statistically significant, there was a trend towards improved survival in this group. The advantages of a free diet, suggested by Reynolds $e t a^{15}$ were not confirmed in this study.

This study was supported by INSERM grant no 650.350. We thank Dr J Kennedy for translating the manuscript.

\section{References}

1 Editorial. Management of hepatic ascites. Lancet 1978; 1: 311-12.

2 Gregory PB, Fogel MR, Sawhney V, Knaver CM, Miller R. Diuresis in the ascitic patient: which is more potent, furosemide or spironolactone? Gastroenterology 1979; 76: 1145.

3 Quintero E, Gines P, Arroyo V, et al. Paracentesis vs diuretics in the treatment of cirrhotics with tense ascites. Lancet 1985; 1: 611 .

4 Sherlock S, Seneviratne B, Scott A, Walker JG. Complications of diuretic therapy in hepatic cirrhosis. Lancet 1966; 1: 1049-52.

5 Reynolds TB, Lieberman FL, Goodman AR. Advantages of treatment of ascites without sodium restriction and without complete removal of excess fluid. Gut 1978; 19: 549-53.

6 Descos L, Gauthier AP, Levy VG, et al. Comparison of six treatments of ascites in patients with liver cirrhosis. Hepatogastroenterology 1983; 30: 15-20.

7 Kaplan EL, Meier P. Non parametric estimation from incomplete observations. J Am Statist Assoc 1958; 53: 457-81.

8 Peto R, Peto J. Asymptotically efficient rank in variant test procedures. J $R$ Statist Soc Ser A 1972; 135: 185-207. 